Research Article

\title{
The Porosity Dynamic Model of the Compacted Broken Coal
}

\author{
Xuefeng Han, ${ }^{1}$ Tingxiang Chu $\mathbb{D},{ }^{2}$ Minggao Yu, ${ }^{3}$ Jiangkun Chao, ${ }^{1}$ Zhihui Ma, ${ }^{1}$ \\ and Xinlei Yang ${ }^{3}$ \\ ${ }^{1}$ School of Safety Science and Engineering, Henan Polytechnic University, Jiaozuo, Henan 454003, China \\ ${ }^{2}$ School of Safety Engineering, North China Institute of Science and Technology, Yanjiao, Hebei 065201, China \\ ${ }^{3}$ State Key Laboratory of Coal Mine Disaster Dynamics and Control, Chongqing University, Chongqing 400044, China
}

Correspondence should be addressed to Tingxiang Chu; ctx1900@126.com

Received 27 April 2020; Revised 6 June 2020; Accepted 1 July 2020; Published 28 July 2020

Academic Editor: Claudio Mazzotti

Copyright (C) 2020 Xuefeng Han et al. This is an open access article distributed under the Creative Commons Attribution License, which permits unrestricted use, distribution, and reproduction in any medium, provided the original work is properly cited.

In order to study the dynamic change law of the porosity of the compacted broken coal under different axial stress loading, based on the environment of the broken and compacted coal in the gob, aiming at the influence of the porosity on the spontaneous combustion of the coal, combined with the fractal theory, the fractal model of the porosity of the broken coal is established. A selfdesigned "testing device for permeability evolution and spontaneous combustion characteristics of crushed coal under pressure" is used to carry out axial loading test on selected coal samples in the gob. By comparing and analyzing the calculated results of void dynamic evolution model and experimental data, it is found that the relative error of void dynamic evolution model is between $2.8 \%$ and $6.2 \%$, which meets the engineering needs. According to the stress-strain curve, initial accumulation state parameters, fractal dimension of initial crushing, and particle size distribution, the change of porosity under different compacted conditions can be predicted by the model, which has certain significance for identifying the change of compacted broken coal porosity and analyzing the process of coal spontaneous combustion and oxidation.

\section{Introduction}

Spontaneous combustion of coal most frequently occurs in gob [1]. Therefore, the study of spontaneous combustion of coal in gob has always been the focus of attention in the field of mine fire prevention and controlling. In the process of coal spontaneous combustion, the mass and heat transfer between fluid and solid media are involved. In this process, porosity and permeability play an intrinsic role in the occurrence and development of coal spontaneous combustion, which mainly affect the air leakage and oxygen transport in gob. Recently, researchers have focused on the porosity and permeability of compacted broken rocks. Karacan [2] presented a novel method for calculating porosity and permeability based on the size distribution of broken rocks in the long-wall gob. Liu et al. [3] proposed a permeability switching model to represent the evolution of coal permeability under variable stress conditions. Ghabezloo et al. [4] proposed a power law for the variation of the permeability with the effective stress by performing constant-head permeability tests with different conditions of confining pressure and pore pressure. The permeability behavior during anthracite coal seam methane production, permeability damage rate, stress sensitivity coefficient, and pore compressibility factor were proposed to evaluate the effective stress-dependent sensitivity characteristics of anthracite coal [5]. Focusing on the strain, porosity, and permeability evolution under the different conditions, $\mathrm{Chu}$ et al. [6] developed a method that included the non-Darcy condition for measuring, calculating, and quantifying the influences of multiple factors on the seepage properties of broken coal. Pappas and Mark [7] studied the mechanical properties of caving materials in gob in detail through 20 sets of uniaxial compression experiments, and the mechanical parameters of rock and the breakage characteristics of bulk rock were obtained. Combining filed data with simulation, Zou et al. [8] proposed a triple porosity/dual permeability model for coal permeability evaluation. By using experimental method, Li et al. [9] obtained the variation of methane permeability combining with effect of stress, pore pressure, and 
temperature; Meng and $\mathrm{Li}$ [10] analyzed the effects of effective stress and gas types on porosity and permeability; Zheng et al. [11] measured permeability behavior of different kinds of gas with respect to changes in effective stresses, pore pressures, and temperatures; Zhu et al. [12] proposed a timelapse three-dimensional permeability with consideration of reservoir anisotropy. Tao et al. [13] found that the first coalification jump (FCJ) has a significant impact on lowrank coal reservoir heterogeneity; during the process of FCJ, the polycondensation of coal molecules and the compaction of coal matrix occur, leading to a rapid decline of moisture, porosity, and permeability. Hou et al. [14] proposed different pore compressibility models to describe the sensitivity of pore systems to stress through experimental study.

Since the introduction of fractal theory, it has been successfully applied to the study of rock mechanics, especially to the study of crack propagation and bifurcation in rock $[15,16]$. By means of theoretical analysis of the relationship between the fractal dimension of coal fragments and dynamite specific energy, Xie and Zhou [17] proposed a mechanical model for describing the size distribution of topcoal fragments and dissipation of blasting energy. According to Schumann's model, the fractal dimension of blasted fragments and in situ rock blocksis was calculated using size distribution curves. Bagde et al. [18] and Zhang et al. [19] established the fractal theoretical relationship between porosity and permeability of the coal seam based on the fractal characteristics of the porosity of the porous media. Pan et al. [20] studied the micropores and fractures of six coal samples with different metamorphic degrees. Their research shows that the porous media has fractal structure and dimension. So, the fractal dimension can be used to predict the porosity of porous media.

The above research methods provide a way to describe the residual coal porosity in gob, but, due to the irregularity of gob caving, the recognition of spontaneous combustion environment in gob is limited. The spontaneous combustion of residual coal in gob is closely related to overburden caving. The caving state of coal and rock determines the accumulation state of broken coal in gob, which is one of the necessary conditions for coal spontaneous combustion. The thickness, porosity, air leakage, and heat transfer of broken coal are greatly affected by overburden caving. The spatial structure and change of residual coal accumulation directly affect the thermal storage environment of coal, the air leakage state, and oxygen concentration distribution in gob. Xu [21] found that, for a specific working face, the main factor affecting the air leakage intensity is the porosity of the residual coal, and the larger the porosity is, the larger the air leakage is. Deng et al. [22] found that, under the condition of certain air leakage intensity in gob, the oxygen volume fraction and distribution have a close relationship with the porosity of the residual coal. According to the process of the coal self-heating in gob, Xia et al. [23] found that the oxygen volume fraction, the thermal conductivity, and the heat release have a close relationship with the seepage field in gob. Tao et al. [24] studied the influence of marcolithotypes on the porosity and fracture heterogeneity of coal seam and found that the bright coal is corresponding to the highest permeability and the best seepage capacity.

Therefore, focusing on coal spontaneous combustion in gob and based on the caving characteristics of residual coal in gob and the fractal theory, a dynamic evolution model of porosity of compacted broken coal was established, which is significant for identifying the porosity change of compacted broken coal and analyzing the process of coal oxidation.

\section{Establishment of Porosity Evolution Model}

2.1. State of Broken Coal in Gob. According to the movement characteristics of strata and the theory of rock pressure, the overlying strata of coal seam are divided into caving zone, fracture zone, and bending zone in vertical direction. With the advance of the working face, the gob behind the working face is formed in turn-coal wall support area, coal rock separation area, and recompaction area-which is shown in Figure 1. Axial overburden stress acts as the main stress in the surrounding space of residual coal accumulation in gob. At the same time, because the deformation and sliding of the coal remains are restricted by the coal wall on both sides, the old cut hole, and the support, the macroscopic performance is mainly axial compaction, and the relative displacement around is fixed. The force acting on it is shown in Figure 2.

In the process of working face mining, the stress in gob is gradually restored, and the overburden stress is gradually increased to the original rock stress level with the advancing of working face, which results in different overlying strata stresses in the caved fractured coal body. Conroy [25] pointed out that the distance of stress recovery in gob is 0.3 times the depth of coal seam; that is, the stress in gob tends to be stable when the distance is 0.3 times the depth of coal seam. Yavuz [26] proposed a method for estimating the stress recovery distance in gob and the characteristics of stress distribution in overlying strata of longwall face are analyzed. With the continuous recovery of stress, the stress loading has a destructive effect on the remaining coal particles. Liang et al. [27] carried out creep tests and particle breakage tests on rockfill using large-scale compression apparatus and pointed out that the rockfill crushing under stress loading mainly includes two aspects: one is the angular crushing and fine deformation of particles corresponding to the main stress compression, and the other is the creep deformation of particles caused by a small amount of crushing, rotation, and filling of voids due to the redistribution of skeleton stress. In the process of axial stress loading, when the volume of the porosity is compressed, due to the contact between the particles, after the stress is applied, the coal samples were dislocated, sliding, even broken, and further powdered, resulting in the particles from large to small. The redistribution of the skeleton stress of coal leads to the breaking and refinement of the edges and corners of the coarse particles or the weak particles and the further adjustment of the particle arrangement, and the particle arrangement is further adjusted, as shown in Figure 3. So, in the process of axial stress loading, when the volume of the porosity is compressed, the contact between the crushed broken coal particles becomes closer. Under the further 


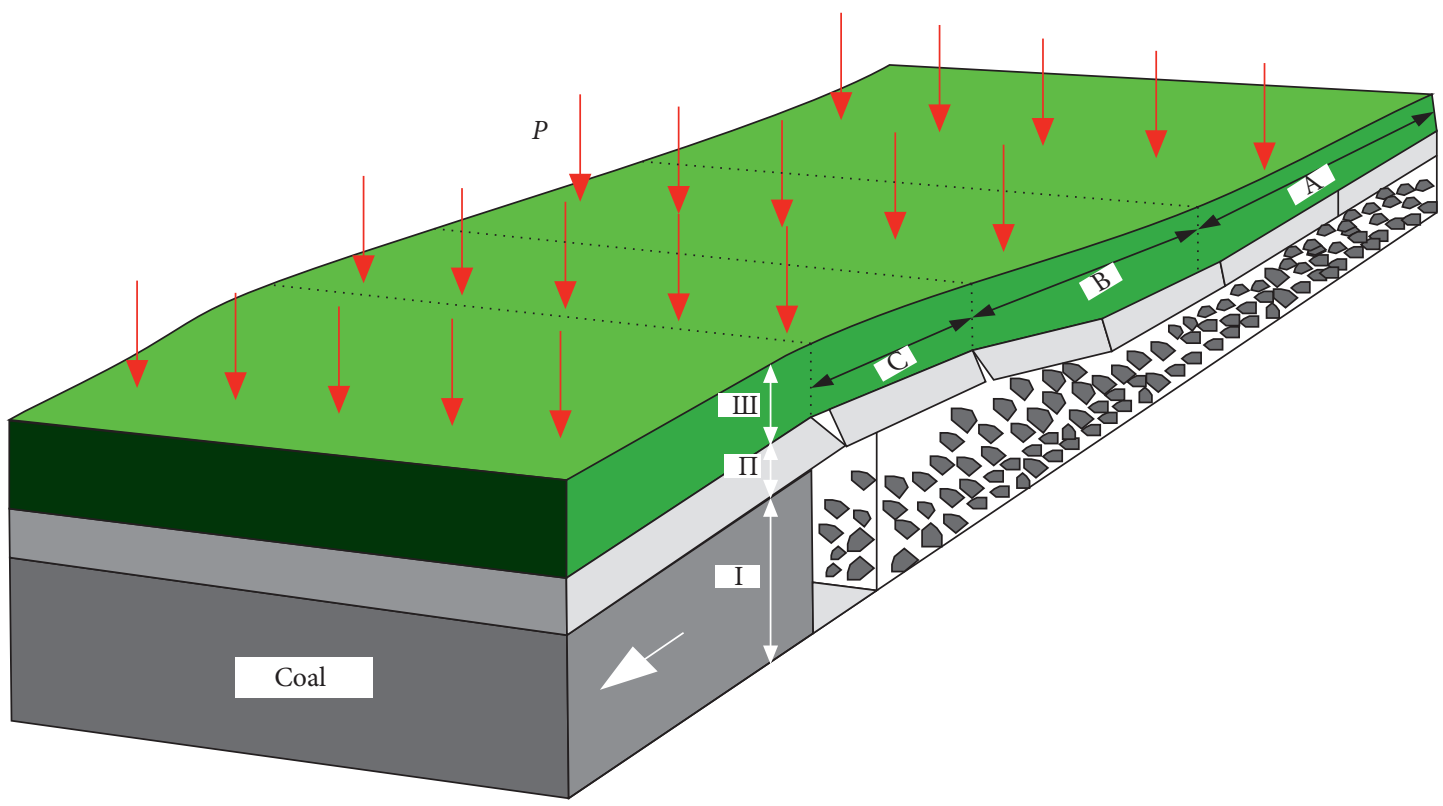

FiguRE 1: Three-dimensional distribution of overburden in gob. (A) recompaction area; (B) coal rock separation area; (C) coal wall support area; (I) caving zone; (II) fracture zone; (III) bending zone.

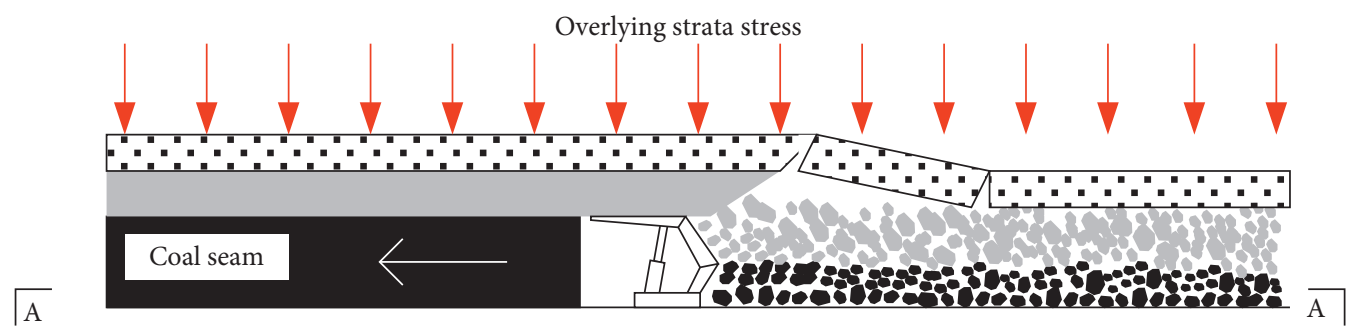

(a)

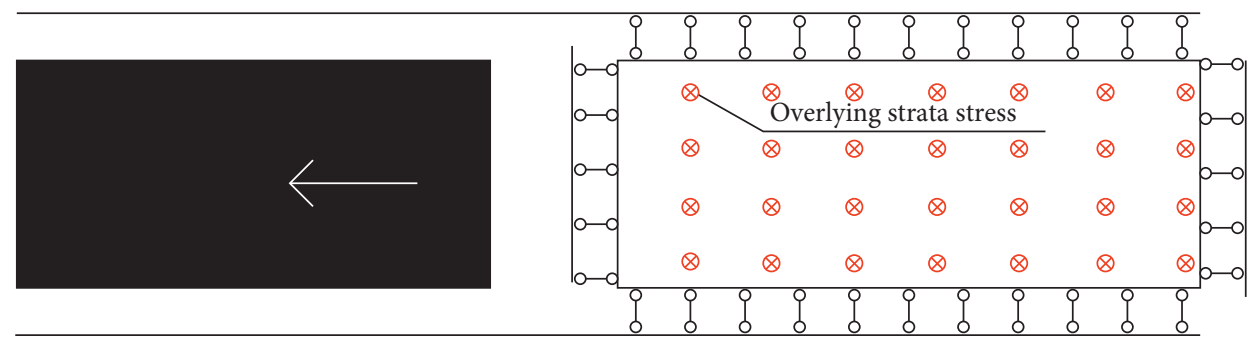

(b)

Figure 2: The stress state of the coal in gob. (a) Working face direction stress. (b) Stress in goaf.

action of stress loading, the crushed broken coal particles move relatively and break again, forming finer particles and filling the effective porosities between the crushed broken coal particles, resulting in the reduction of the crushing expansion coefficient, porosity, and permeability of the crushed broken coal particles.

In the process of working face mining, the stress in gob is gradually restored, and the overburden stress is gradually increased to the original rock stress level with the advancing of working face. The different stress in gob will affect the compaction state of broken coal and rock in gob. Therefore, affected by stress restoration, the broken coal in gob will be further smashed and compacted; this will affect the distribution of its porosity and permeability. Porosity and permeability are the key parameters in the multifield coupling process of coal spontaneous combustion and play an important role in the flow pattern, oxygen concentration distribution, and temperature distribution in gob. Therefore, it is of great practical significance to study the dynamic porosity evolution of confined fractured coal in gob.

2.2. Fractal Model of Porosity. According to the research results of Tyler and Wheatcraft [28], the samples can be 

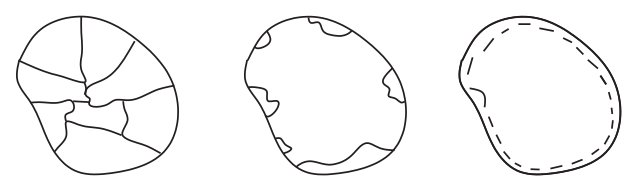

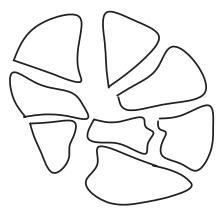

(a)

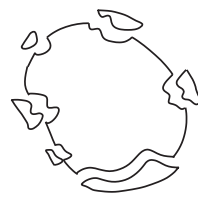

(b)

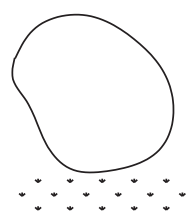

(c)

Figure 3: Particle breakage types. (a) Fracture. (b) Broken. (c) Milled.

screened by sieves of different diameters, and the functional relationship between the mass of the samples under sieve and the mass of the total samples can be established to analyze the distribution of the size of the residual coal.

The fractal relationship between particle mass and particle size can be obtained by assuming that $M_{1}\left(d_{i}\right)$ is the mass of the sample under sieve $d_{i}, M_{\mathrm{t}}$ is the total mass of the sample, and the maximum particle size is $d_{\max }$, assuming that the particle has the same density:

$$
\frac{M_{1}\left(d_{i}\right)}{M_{\mathrm{t}}}=\left(\frac{d_{i}}{d_{\max }}\right)^{3-D} \text {. }
$$

If the logarithm is taken on both sides of equation (1), there are

$$
\ln \left[\frac{M_{1}\left(d_{i}\right)}{M_{\mathrm{t}}}\right]=(3-D) \ln \left(\frac{d_{i}}{d_{\max }}\right)
$$

Through physical screening and weighing statistics, the statistical value of $M_{1}\left(d_{i}\right) / M_{\mathrm{t}}$ can be obtained, and the slope $k$ of the straight line part can be obtained by linear regression, that is, the value of $(3-D)$ in equation (2), and then the fractal dimension $D$ of coal fragmentation can be obtained.

The broken coal porosity is the ratio of the void volume of broken coal to the volume of the whole apparent accumulation body. If the particle size of crushed coal is $d$, according to the definition of density, we have

$$
\frac{M_{1}\left(d_{i}\right)}{M_{\mathrm{t}}}=\frac{\rho V\left(d_{i}\right)}{\rho V}=\left(\frac{d_{i}}{d_{\max }}\right)^{3-D},
$$

where $V\left(d_{i}\right)$ is the fractal volume of residual coal whose particle characteristic size is less than $d_{i}$ and $V$ is the apparent total volume.

For partially broken coal with particle size less than $d_{i}$, the accumulative volume is as follows:

$$
V\left(d_{i}\right)=\frac{V M_{1}\left(d_{i}\right)}{M_{\mathrm{t}}}=\frac{M}{\rho}\left(\frac{d_{i}}{d_{\max }}\right)^{3-D} .
$$

When the particle size is in the interval $\left(d_{i}, d_{i}+d d_{i}\right)$, the accumulation volume is

$$
d V\left(d_{i}\right)=\frac{M}{\rho} d\left(\frac{d_{i}}{d_{\max }}\right)^{3-D} .
$$

The total fractal volume of broken coal is as follows:

$$
V=\int_{d_{\min }}^{d_{\max }} \frac{M}{\rho} d\left(\frac{d}{d_{\max }}\right)^{3-D}=\frac{M}{\rho} \frac{d_{\max }^{3-D}-d_{\min }^{3-D}}{d_{\max }^{3-D}} .
$$

From the definition of void fraction, it is concluded that

$$
\phi_{0}=\frac{V-\left(M / \rho_{s}\right)}{V}=1-\frac{\rho_{0} d_{\max }^{3-D}}{\rho_{s}\left(d_{\max }^{3-D}-d_{\min }^{3-D}\right)},
$$

where $\phi_{0}$ is the original fragmentation and expansion porosity of broken coal body; $\rho_{0}$ is the density of residual coal from original fragmentation and expansion; and $\rho_{s}$ is the density of coal seam.

2.3. The Effects of Stress to Bulk Solid. McDowell et al. [29] studied the variation of porosity by uniaxial loading experiment and particle distribution model:

$$
d \varphi=\Lambda \sigma^{(m(D-1) / 2)-2} d \sigma,
$$

where $D$ is the fractal dimension of fragmentation; $m$ is the Weibull distribution coefficient of particles; $\sigma$ is the axial loading strength; and $\Lambda$ is the plastic index of materials, which can be regarded as a constant for specific materials.

The physical process of broken coal in gob can be investigated by the axial compaction experiment under the condition of lateral limit. Assuming that the initial mass of coal sample is $m_{0}$, the initial broken bulge density is $\rho_{0}$, the height of coal sample in the natural broken bulge stacking device is $h_{0}$, the initial porosity is $\phi_{0}$, the density of compacted broken coal is $\rho$, the strain is $\varepsilon_{v}$, and the porosity is $\phi$ in the process of confining pressure. The height of coal sample under different stress states after confining is $h_{\sigma}=\left(1-\varepsilon_{v}\right) h_{0}$. During the compression process of broken coal, it is continuously compacted, and the void volume decreases with the degree of compaction. From the conservation of mass, it is obtained that

$$
\frac{\rho}{\rho_{0}}=\frac{1}{1-\varepsilon_{v}} \text {. }
$$


TABLE 1: The initial mass content of each grain group.

\begin{tabular}{lcccccccc}
\hline Coal sample & Particle size $(\mathrm{mm})$ & $d<0.3$ & $d<0.6$ & $d<1$ & $d<3$ & $d<6$ & $d<10$ & $d<15$ \\
\hline \multirow{2}{*}{$1 \#$} & Underscreening quality & 0.092 & 0.178 & 0.247 & 0.47 & 0.695 & 0.968 & 1.249 \\
& Mass ratio & 0.0736 & 0.1425 & 0.1978 & 0.3763 & 0.5564 & 0.7750 \\
2\# & Underscreening quality & 0.044 & 0.083 & 0.132 & 0.317 & 0.565 & 0.865 & 1.231 \\
& Mass ratio & 0.0357 & 0.0674 & 0.1072 & 0.2575 & 0.4590 & 0.7027 & 1 \\
\multirow{2}{*}{$3 \#$} & Underscreening quality & 0.05 & 0.107 & 0.159 & 0.395 & 0.631 & 0.983 & 1.303 \\
& Mass ratio & 0.0384 & 0.0821 & 0.1220 & 0.3031 & 0.4843 & 0.7544 \\
\hline
\end{tabular}

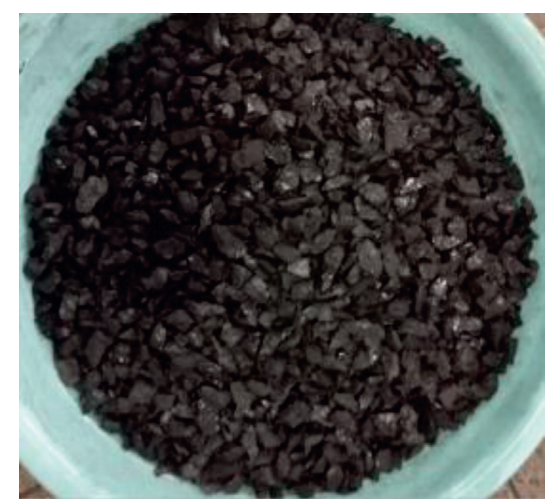

(a)

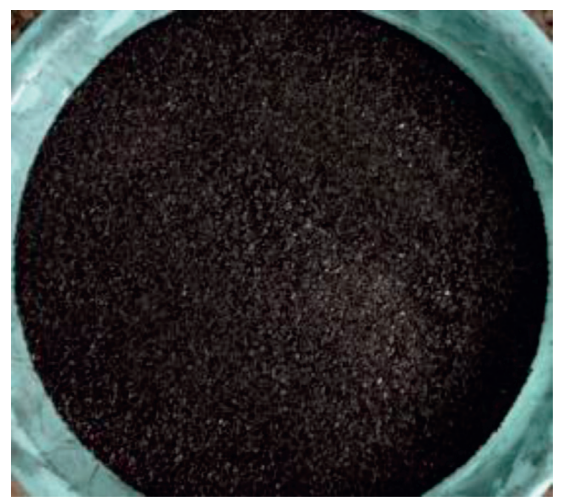

, (d)

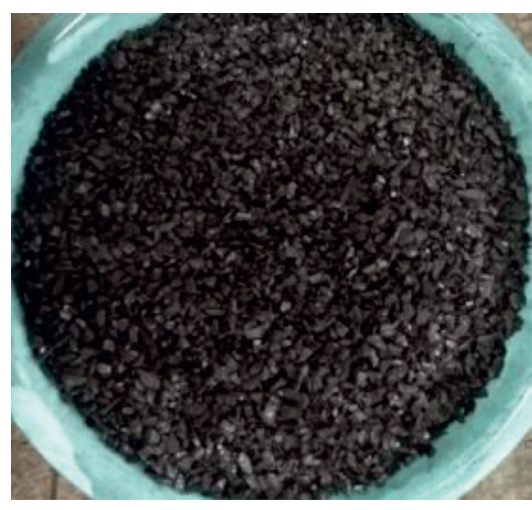

(b)

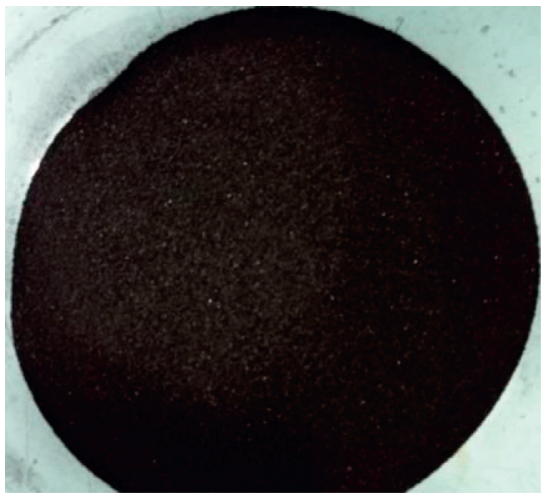

(e)

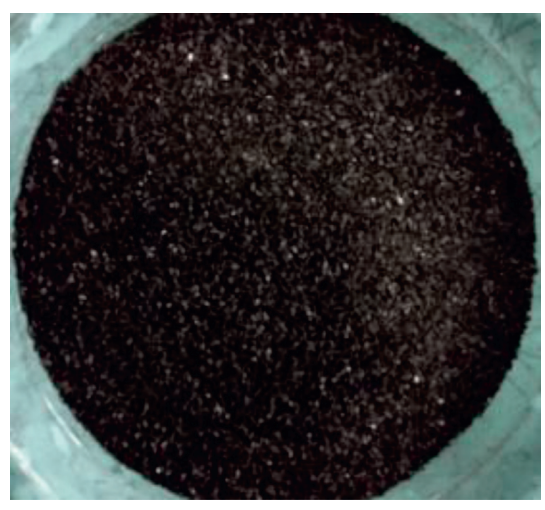

(c)

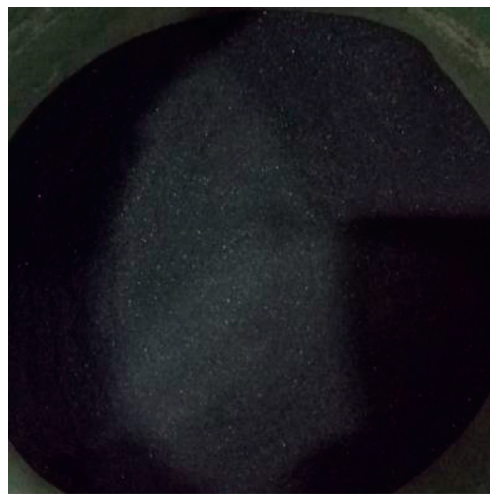

(f)

Figure 4: Screening coal samples with different particle sizes: (a) $10 \leq d \leq 15 \mathrm{~mm}$ coal sample, (b) $6 \leq d \leq 10 \mathrm{~mm}$ coal sample, (c) $3 \leq d \leq 6 \mathrm{~mm}$ coal sample, (d) $1 \leq d \leq 3 \mathrm{~mm}$ coal sample, (e) $0.6 \leq d \leq 1 \mathrm{~mm}$ coal sample, and (f) $0.3 \leq d \leq 0.6 \mathrm{~mm}$ coal sample.

According to the definition of porosity, the porosity of compacted broken coal can be expressed as follows:

$$
\phi=\frac{V_{P}}{V}=\frac{(1 / 4) \phi_{0} \pi d^{2} h_{0}-(1 / 4) \pi d^{2} h_{0} \varepsilon_{v}}{(1 / 4) \pi d^{2}\left(1-\varepsilon_{v}\right) h_{0}}=\frac{\phi_{0}-\varepsilon_{v}}{1-\varepsilon_{v}} .
$$

The stress-strain relationship during compaction can be expressed as [4]

$$
\sigma_{v}=A e^{b \varepsilon_{v}}
$$

where $\varepsilon_{v}$ is the axial strain of rock, $\sigma_{v}$ is the axial compressive stress, and $A, b$ is the regression coefficient of compaction.

Combining (7) and (11) and entraining (10), the dynamic porosity evolution model of compacted broken coal body is as follows:

$$
\begin{aligned}
\phi & =1-\frac{\rho_{0} d_{\max }^{3-D}}{\rho_{s}\left(d_{\max }^{3-D}-d_{\min }^{3-D}\right)\left(1-\varepsilon_{v}\right)} \\
& =1-\frac{\rho_{0} d_{\max }^{3-D}}{\rho_{s}\left(d_{\max }^{3-D}-d_{\min }^{3-D}\right)\left(1-\ln \left(\sigma_{v} / A\right) / b\right)} .
\end{aligned}
$$

Formula (12) shows that the porosity fraction of broken coal under confined pressure is related to the stress and strain, particle size distribution, and confined state of coal. The change of stress in the granular system will lead to the change of gradation and stress strain of the granular system, while the porosity of the confined granular system will change dynamically. 


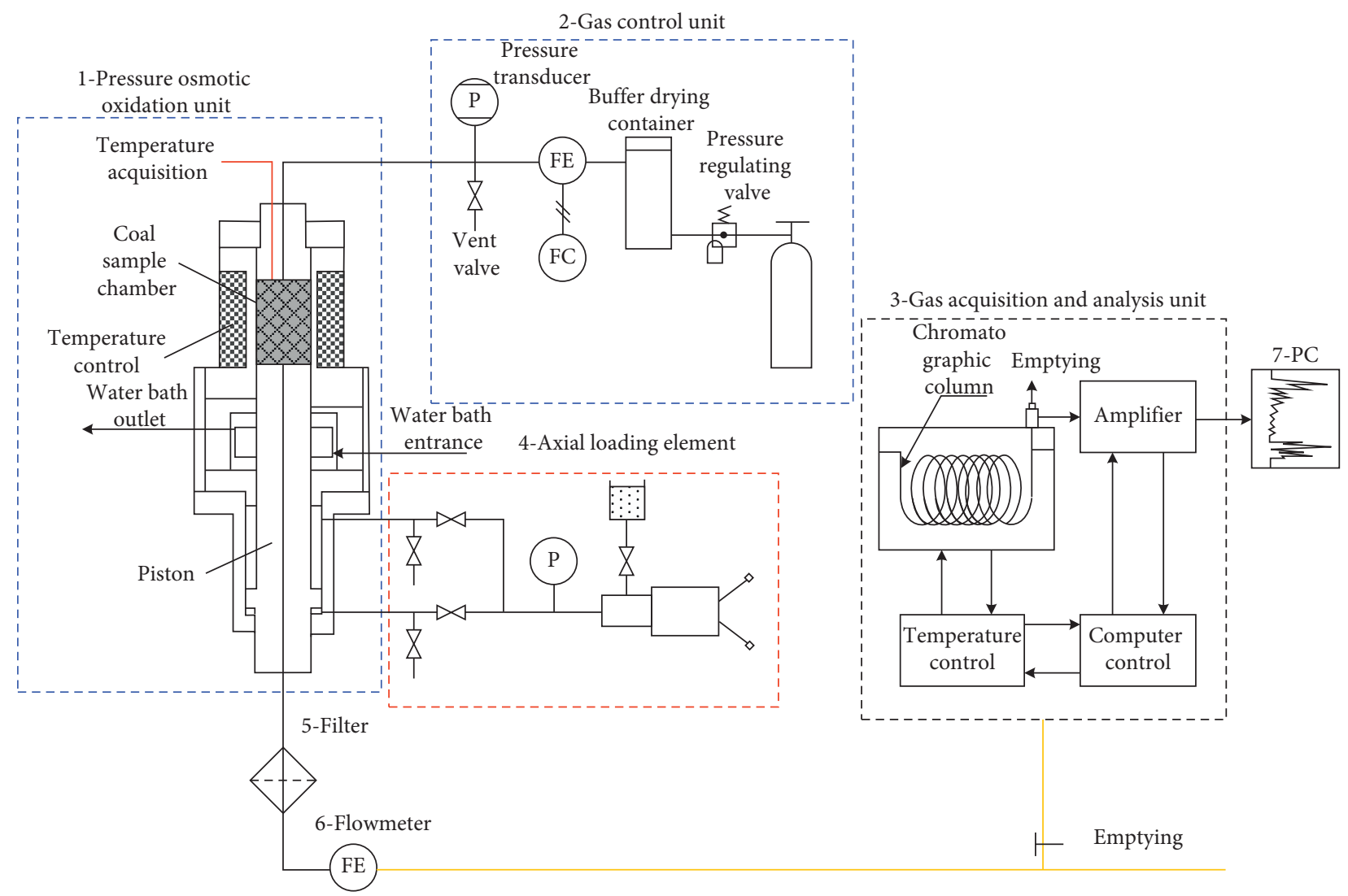

FIGURE 5: The porosity measurement of the compacted experiment of broken coal: (1) pressure osmotic oxidation unit; (2) gas control unit; (3) gas acquisition and analysis unit; (4) axial loading element; (5) filter; (6) flowmeter; (7) PC.

\section{Experiment and Analysis}

3.1. Experiment. In a working face of Gengcun Coal Mine, in China, three caving mixed residual coals at different positions behind the support along the inclination of the working face were selected as experimental coal samples. In order to calculate the porosity of the coal sample, the true density of the coal sample is tested first, and the true density of the experimental coal sample is $1.59 \mathrm{~kg} / \mathrm{m}^{3}$. Mixed coal samples with particle size less than $15 \mathrm{~mm}$ were selected as experimental coal samples in the laboratory. After natural air-drying for $24 \mathrm{~h}$, screening was carried out to determine the gradation composition of residual coal accumulations with particle size less than $15 \mathrm{~mm}$ in the natural fragmentation area, as shown in Table 1. The screened coal sample is shown in Figure 4. Among them, coal samples 1\#, 2\#, and 3\# are prepared two copies each, keeping the same gradation, one for stress and strain test and the other for fractal dimension determination under specific axial loading stress.

Based on the stress environment of the residual coal in gob, a self-design experimental facility "Testing Device for the Permeability Evolution and Spontaneous Combustion Characteristics of Pressure-bearing Coal" is shown in Figure 5. Through the device, the axial loading experiment can be carried out on the selected coal samples in the gob. By setting different axial loading strength and rescreening, the gradation composition of the loaded coal samples and the porosity of the compacted broken coal samples under pressure can be determined.

When applying the axial stress to the coal samples, the stress test points were set every $3 \mathrm{MPa}$ in the range of $0-15 \mathrm{MPa}$. The pore pressure test points were set every $0.05 \mathrm{MPa}$ in the range of $0.2-0.35 \mathrm{MPa}$. The specific experimental steps are as follows:

(i) Lower the piston guide rod at the bottom of the coal sample chamber to the lowest point, open the removable plug at the top of the coal sample chamber, mix the prepared coal samples evenly and then load them into the coal sample chamber, and cover the removable plug at the top of the coal sample chamber.

(ii) Check the air tightness of the coal sample chamber, record the initial height of the coal sample, fix the positioning and move the sensor, and record the initial displacement displayed by the displacement sensor.

(iii) Add the axial pressure to $3 \mathrm{MPa}$, and record the displacement displayed by the displacement sensor.

(iv) Add the axial pressure to $6 \mathrm{~Pa}, 9 \mathrm{MPa}, 12 \mathrm{MPa}$, and $15 \mathrm{MPa}$ in turn, and repeat the data in step (iii). Record and sort out the experimental data.

3.2. Experimental Results. According to formula (2) and Table 1, fractal dimension of original coal sample can be 
TABLE 2: The fractal dimension and porosity of the initial coal sample.

\begin{tabular}{lccccccccc}
\hline $\begin{array}{l}\text { Coal } \\
\text { sample }\end{array}$ & $\begin{array}{c}\rho_{s} \\
\left(\mathrm{~kg} / \mathrm{m}^{3}\right)\end{array}$ & $\begin{array}{c}\text { Quality } \\
(\mathrm{kg})\end{array}$ & $D$ & $\begin{array}{c}d_{\min } \\
(\mathrm{mm})\end{array}$ & $\begin{array}{c}d_{\max } \\
(\mathrm{mm})\end{array}$ & $\begin{array}{c}h_{0} \\
(\mathrm{~mm})\end{array}$ & $\begin{array}{c}\text { Section area of } \\
\text { device }\left(\mathrm{m}^{2}\right)\end{array}$ & $\begin{array}{c}\text { Experimental } \\
\text { result }\end{array}$ & $\begin{array}{c}\text { Theoretical } \\
\text { calculation } \\
\text { porosity }\end{array}$ \\
\hline $1 \#$ & $1.55 * 10^{3}$ & 1.249 & 2.369 & 0.01 & 15.0 & 134 & & 0.222 & 0.2002 \\
$2 \#$ & $1.55 * 10^{3}$ & 1.231 & 2.158 & 0.01 & 15.0 & 130 & 0.00785 & 0.221 & 0.2101 \\
3\# & $1.55 * 10^{3}$ & 1.303 & 2.202 & 0.01 & 15.0 & 140 & & 0.235 & 0.2211 \\
\hline
\end{tabular}

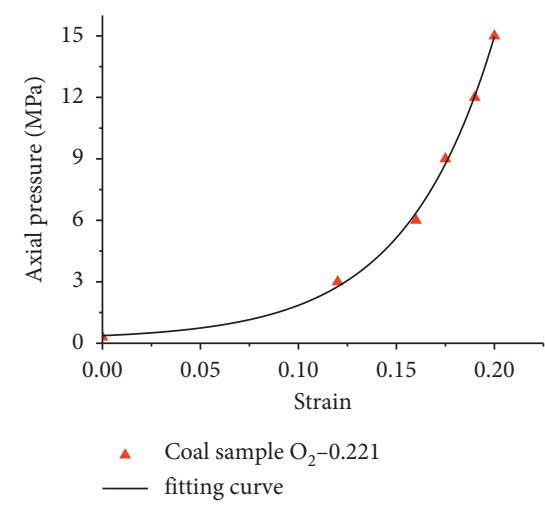

(a)

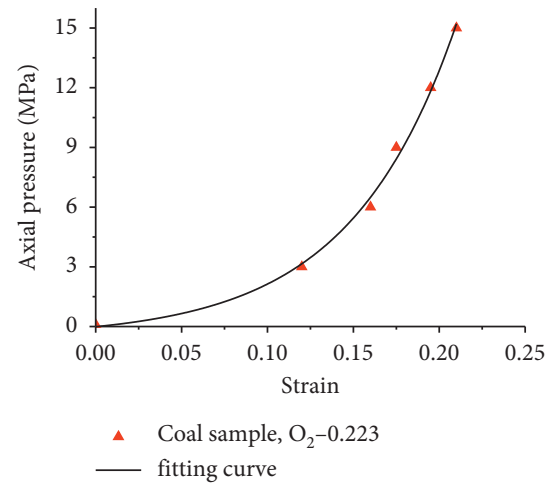

(b)

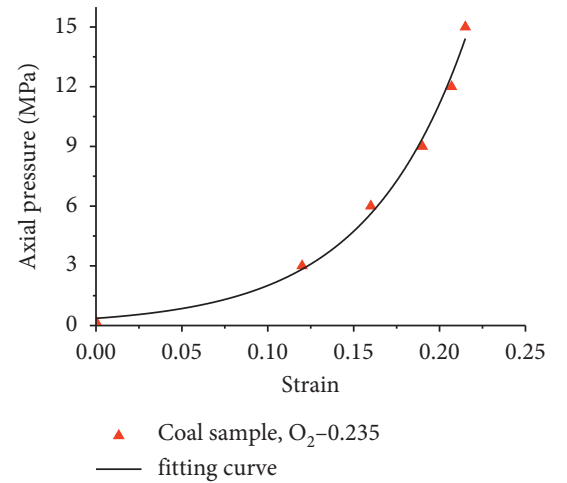

(c)

FIgURE 6: The stress-strain curve of the compacted broken coal. (a) Coal sample 1\#. (b) Coal sample 2\#. (c) Coal sample 3\#.

TABLE 3: The fitting parameters of the stress-strain curve.

\begin{tabular}{lcccc}
\hline Coal sample & Parameter $A$ & Parameter $b$ & Fitting function & Fitting degree \\
\hline $1 \#$ & 0.2698 & 19.317 & $\sigma_{v}=0.2698 e^{19.317 \varepsilon_{v}}$ & 0.9906 \\
$2 \#$ & 0.2997 & 19.792 & $\sigma_{v}=0.2997 e^{19.792 \varepsilon_{v}}$ & 09942 \\
$3 \#$ & 0.3605 & 17.263 & $\sigma_{v}=0.3605 e^{17.263 \varepsilon_{v}}$ & 0.9882 \\
\hline
\end{tabular}

TABLE 4: The gradation and fractal dimension under special axial pressure.

\begin{tabular}{lccccccccc}
\hline Loading of coal sample & Particle size $(\mathrm{mm})$ & $d \leq 0.3$ & $d \leq 0.6$ & $d \leq 1$ & $d \leq 3$ & $d \leq 6$ & $d \leq 10$ & $d \leq 15$ & Fractal dimension \\
\hline $1 \#$ & Underscreening quality & 0.133 & 0.277 & 0.399 & 0.646 & 0.86 & 1.075 & 1.239 & 2.5064 \\
$9 \mathrm{MPa}$ & Mass ratio & 0.107 & 0.224 & 0.322 & 0.521 & 0.694 & 0.868 & 1 & 1.225 \\
$2 \#$ & Underscreening quality & 0.138 & 0.266 & 0.38 & 0.631 & 0.846 & 1.045 & 1.225 & 2.5054 \\
$12 \mathrm{MPa}$ & Mass ratio & 0.113 & 0.217 & 0.310 & 0.515 & 0.691 & 0.853 & 1 & 1.144 \\
$3 \#$ & Underscreening quality & 0.178 & 0.325 & 0.448 & 0.707 & 0.932 & 1.289 & 2.5531 \\
$15 \mathrm{MPa}$ & Mass ratio & 0.138 & 0.252 & 0.348 & 0.548 & 0.723 & 0.888 & 1 & \\
\hline
\end{tabular}

obtained by regression. The calculation results are shown in Table 2.

As can be seen from Table 2, through gradation screening and fractal dimension regression of original coal samples, the porosity of $1 \#, 2 \#$, and $3 \#$ coal samples under natural accumulation state has been obtained by using the fractal model formula of porosity (7). The porosity of 1\#, 2\#, and $3 \#$ coal samples is compared with that calculated by the definition of porosity. It is found that the relative error calculated by the fractal model and the porosity definition is between $4.9 \%$ and $9.8 \%$.

In order to study the porosity under confined condition, the confined experiments of coal samples $1 \#, 2 \#$, and $3 \#$ were carried out, respectively. The stress-strain curves of three coal samples have been obtained, as shown in Figure 6. The fitting function of the stress-strain curve of three coal samples is shown in Table 3, and the fitting function has a high degree of fit.

Combining formula (2), the fractal dimension of coal samples $1 \#, 2 \#$, and $3 \#$ after loading $9 \mathrm{MPa}, 12 \mathrm{MPa}$, and $15 \mathrm{MPa}$ has been obtained by regression.

3.3. Analyzing. Through the axial loading experiments of coal samples $1 \#, 2 \#$, and $3 \#$, according to the quality of coal samples, true density of coal samples, and compaction displacement, the experimental porosity under different stress states can be obtained. According to the experimental data in Tables 2 and 4 and the porosity model in formula (12), the porosity can be determined, as shown in Table 5. 
TABLE 5: The results of the fractal porosity of the compacted broken coal.

\begin{tabular}{lcccccc}
\hline $\begin{array}{l}\text { Coal } \\
\text { sample }\end{array}$ & $\begin{array}{c}\text { Axial stress } \\
(\mathrm{MPa})\end{array}$ & $\begin{array}{c}\text { Fractal } \\
\text { dimension }\end{array}$ & $\begin{array}{c}\text { Axial } \\
\text { strain }\end{array}$ & $\begin{array}{c}\text { Experimental } \\
\text { result }\end{array}$ & $\begin{array}{c}\text { Theoretical model: formula } \\
(15)\end{array}$ & Relative error (\%) \\
\hline $1 \#$ & 9 & 2.5064 & 0.1755 & 0.0545 & 0.0526 & 3.5 \\
$2 \#$ & 12 & 2.5054 & 0.1864 & 0.0425 & 0.0437 & 2.8 \\
$3 \#$ & 15 & 2.5531 & 0.2159 & 0.0243 & 0.0228 & 6.2 \\
\hline
\end{tabular}

The porosity values of coal samples $1 \#, 2 \#$, and $3 \#$ under $9 \mathrm{MPa}, 12 \mathrm{MPa}$, and $15 \mathrm{MPa}$ loading have been obtained through experimental tests and theoretical calculations. By comparing the two values, the relative errors of the three coal samples are $3.5 \%, 2.8 \%$, and $6.2 \%$, respectively. The relative errors are relatively small, which indicates that the porosity model established can be used to predict the porosity changes in different stress states.

Through experiments and theoretical calculations, it is found that the relative errors of porosity values obtained from experimental tests and model calculations are small in the natural fragmentation and pressure states of $1 \#, 2 \#$, and $3 \#$ coal samples, which can basically meet the needs of engineering. With the fractal model of porosity fraction of broken coal under confined pressure, the porosity fraction evolution of broken coal under different stress states can be predicted.

\section{Conclusions}

In order to study the change rule of the porosity of the broken coal under different axial stress loading, a porosity fractal model of the compacted broken coal was established in this paper. The self-designed device was used to carry out the axial loading test on the coal sample, which verifies the reliability of the model. The model established in this paper can predict the change of porosity of coal under different compacted conditions, which has a certain significance for the analysis of spontaneous combustion and oxidation of coal.

(1) Based on the compacted environment of broken coal in gob, focusing on the effects of the porosity on spontaneous combustion of coal, a porosity fractal model of the compacted broken coal was established combining with the fractal theory.

(2) The self-developed device was used to carry out the axial loading test; the relative error between the calculated results of the porosity dynamic evolution model and the experimental data is between $2.8 \%$ and $6.2 \%$, and the reliability of the model was verified.

(3) According to the initial accumulation state parameters, initial fractured fractal dimension, and particle size distribution, this model can predict the change of porosity under different compaction conditions, which is of theoretical and practical significance in analyzing the spontaneous combustion and oxidation process of abandoned coal in gob.

\section{Data Availability}

The data used to support the findings of this study are available from the corresponding author upon request.

\section{Conflicts of Interest}

The authors declare that they have no conflicts of interest.

\section{Acknowledgments}

This work was supported by the National Natural Science Foundation of China (51774114) and Basic Scientific Research Business in Central Universities (3142018028 and 3142018002).

\section{References}

[1] C. Kuenzer and G. B. Stracher, "Geomorphology of coal seam fires," Geomorphology, vol. 138, no. 1, pp. 209-222, 2012.

[2] C. O. Karacan, "Prediction of porosity and permeability of caved zone in longwall gobs," Transport in Porous Media, vol. 82, no. 2, pp. 413-439, 2010.

[3] J. Liu, J. Wang, Z. Chen, S. Wang, D. Elsworth, and Y. Jiang, "Impact of transition from local swelling to macro swelling on the evolution of coal permeability," International Journal of Coal Geology, vol. 88, no. 1, pp. 31-40, 2011.

[4] S. Ghabezloo, S. Jean, S. Guedon, and F. Martineau, "Effective stress law for the permeability of a limestone," International Journal of Rock Mechanics \& Mining Sciences, vol. 46, no. 2, pp. 297-306, 2009.

[5] Y. Meng, Z. Li, and F. Lai, "Experimental study on porosity and permeability of anthracite coal under different stresses," Journal of Petroleum Science and Engineering, vol. 133, pp. 810-817, 2015.

[6] T. Chu, M. Yu, and D. Jiang, "Experimental investigation on the permeability evolution of compacted broken coal," Transport in Porous Media, vol. 116, no. 2, pp. 847-868, 2017.

[7] D. M. Pappas and C. Mark, "Behavior of simulated long wall gob material," Report of Investigations RI No. 9458, US Department of Interior, US Bureau of Mines, Washington, DC, USA, 1993.

[8] M. Zou, C. Wei, H. Yu, and L. Song, "Modeling and application of coalbed methane recovery performance based on a triple porosity/dual permeability model," Journal of Natural Gas Science and Engineering, vol. 22, pp. 679-688, 2015.

[9] Y. Li, C. Zhang, D. Tang et al., "Coal pore size distributions controlled by the coalification process: an experimental study of coals from the Junggar, Ordos and Qinshui basins in China," Fuel, vol. 206, pp. 352-363, 2017.

[10] Y. Meng and Z. Li, "Triaxial experiments on adsorption deformation and permeability of different sorbing gases in anthracite coal," Journal of Natural Gas Science and Engineering, vol. 46, pp. 59-70, 2017.

[11] G. Zheng, Z. Pan, Z. Chen et al., "Laboratory study of gas permeability and cleat compressibility for CBM/ECBM in Chinese coals," Energy Exploration \& Exploitation, vol. 30, no. 3, pp. 451-476, 2012.

[12] H. Zhu, X. Tang, Q. Liu et al., "Permeability stress-sensitivity in $4 \mathrm{D}$ flow-geomechanical coupling of Shouyang CBM 
reservoir, Qinshui Basin China,” Fuel, vol. 232, pp. 817-832, 2018.

[13] S. Tao, S. D. Chen, D. Z. Tang, X. Zhao, H. Xu, and S. Li, "Material composition, pore structure and adsorption capacity of low-rank coals around the first coalification jump: a case of eastern Junggar Basin, China," Fuel, vol. 211, pp. 804-815, 2018.

[14] X. Hou, Y. Zhu, Y. Wang, and Y. Liu, "Experimental study of the interplay between pore system and permeability using pore compressibility for high rank coal reservoirs," Fuel, vol. 254, Article ID 115712, 2019.

[15] H. Xie and D. J. Sanderson, "Fractal effects of crack propagation on dynamic stress intensity factors and crack velocities," International Journal of Fracture, vol. 74, no. 1, pp. 29-42, 1995.

[16] H. Xie, "Effects of fractal crack," Theoretical and Applied Fracture Mechanics, vol. 23, no. 3, pp. 235-244, 1995.

[17] H. Xie and H. W. Zhou, "Application of fractal theory to topcoal caving," Chaos, Solitons and Fractals, vol. 36, no. 4, pp. 797-807, 2008.

[18] M. N. Bagde, A. K. Raina, A. K Chakraborty, and J. L. Jethwa, "Rock mass characterization by fractal dimension," Engineering Geology, vol. 63, no. 1-2, pp. 141-155, 2002.

[19] X. Zhang, S. Zhang, Y. Yang, P. Zhang, and G. Wei, "Numerical simulation by hydraulic fracturing engineering based on fractal theory of fracture extending in the coal seam," Journal of Natural Gas Geoscience, vol. 1, no. 4, pp. 319-325, 2016.

[20] J. Pan, K. Wang, Q. Hou, Q. Niu, H. Wang, and Z. Ji, "Micropores and fractures of coals analysed by field emission scanning electron microscopy and fractal theory," Fuel, vol. 164, pp. 277-285, 2016.

[21] J. Xu, Judgment Theory of Coal Spontaneous Combustion Risk Zone, Coal Industry Publishing House, Beijing, China, 2001, in Chinese.

[22] J. Deng, Y. Xiao, Q. Li, J. Lu, and H. Wen, "Experimental studies of spontaneous combustion and anaerobic cooling of coal," Fuel, vol. 157, pp. 261-269, 2015.

[23] T. Xia, X. Wang, F. Zhou, J. Kang, J. Liu, and F. Gao, "Evolution of coal self-heating processes in longwall gob areas," International Journal of Heat and Mass Transfer, vol. 86, pp. 861-868, 2015.

[24] S. Tao, Z. J. Pan, S. L. Tang, and S. D. Chen, "Current status and geological conditions for the applicability of CBM drilling technologies in China: a review," International Journal of Coal Geology, vol. 202, pp. 95-108, 2019.

[25] J. P. Conroy, "Influence of elevated atmospheric $\mathrm{CO}_{2}$ concentrations on plant nutrition," Australian Journal of Botany, vol. 40, no. 5, pp. 445-456, 1992.

[26] H. Yavuz, "An estimation method for cover pressure re-establishment distance and pressure distribution in the goaf of longwall coal mines," International Journal of Rock Mechanics \&Mining Sciences, vol. 41, no. 2, pp. 193-205, 2004.

[27] J. Liang, H. Liu, and Y. Gao, "Greepmechanism and breakage behaviour of rockfill," Rockand Soil Mechanics, vol. 24, no. 3, pp. 479-483, 2003.

[28] S. W. Tyler and S. W. Wheatcraft, "Fractal scaling of soil particle size distributions: analysis and limitations," Soil Science Society of America Journal, vol. 56, no. 2, pp. 363-369, 1992.

[29] G. R. McDowell, M. D. Bolton, and D. Robertson, "The fractal crushing of granular materials," Journal of the Mechanics and Physics of Solids, vol. 44, no. 12, pp. 2079-2101, 1996. 